\title{
L1 Gene Molecular Variation of Human Papilloma Virus Type 16 from Cervical Cancer Patient
}

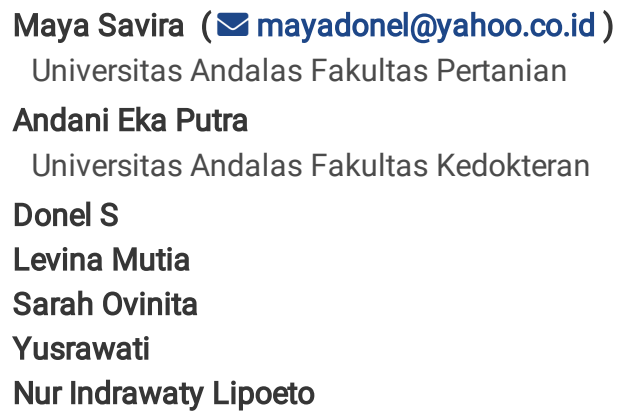

Research

Keywords: cervical cancer, type 16 HPV L1 gene, molecular variation

Posted Date: June 19th, 2020

DOI: https://doi.org/10.21203/rs.3.rs-32572/v1

License: (c) (i) This work is licensed under a Creative Commons Attribution 4.0 International License. Read Full License 


\section{Abstract}

Background: Cervical cancer is the second most cancer in the world after breast cancer, this cancer is caused by infection of high risk Human Papillomavirus (HPV) type 16. It is often found in cervical cancer whose genome structure is composed of L1 proteins. L1 protein makes up the viral capsid that has an important role to infect the cervical epithelium. Several studies have found the differences in HPV nucleotides variants that lead to changes in amino acids that can disrupt the structure, the nature function of the virus itself, and ultimately lead to changes in biological functions including host immunological recognition. Variation of the L1 gene will also affect the effectiveness of existing vaccines.

Methods: This research is a descriptive study conducted at the laboratory of microbiology at the Faculty of Medicine at Andalas Padang University from February to August 2018 which aims to look at the molecular variations of the L1 HPV type 16 gene and see phylogenic kinship.

Results: This study obtained SNPs (Single Nucleotide Polymorphism) on all HPV 16 samples in the form of C / G (6240), A / G (6432), T / G (6686), C / T (6823) and insertion of nucleotide bases ACT (6901) ) and followed by GAT base deletions (6953) variations occurring along the observed sample isolate sequences.

Conclusion: There are molecular variations of the L1 HPV type 16 gene which can cause different host immune responses. Phylogenic kinship of HPV type 16 isolate in Riau is close to Asian-American isolate.

\section{Introduction}

Cervical cancer is the second most malignancies in women in the world (Bruni et al., 2017). Concerning the epidemiology, it is estimated there are 528,000 new cases and 266,000 deaths in 2012 (Farley et al., 2015). If the number of cases continues to increase, it is estimated that by 2025 cervical cancer in the world will reach 20 million new cases. The main risk factor for cervical cancer is related to Human papillomavirus (HPV) infection in the cervical epithelium (Akyar et al., 2013; Manga et al., 2015; Nurcahyanti, 2016).

It is estimated that $5 \%$ of cancers in humans are caused by Human papillomavirus (HPV) infections, some of these cancers originate from cervical cancer. Type $16 \mathrm{HPV}$ is a major cause of cervical cancer, with percentage, respectively, $45.5 \%$ in worldwide and $60 \%$ in Indonesia (Bruni et al., 2017). It is reported that 70\% of cervical cancer caused by the infection of oncogenic type of HPV (high risk), and it is associated with anogenital cancers in men and women, such as cancer of the penis, vulva, vagina, anal, and oropharyngeal cancer (Setiawati, 2014). Approximately there are 100 different subtypes of HPV with different variations in potency and oncogenic, and which specifically infecting anogenital area are HPV types $16,18,31,33,35,39,45,52,52,56,58,66$, and 69 (Faridi et al., 2011)

In the study of cervical cancer samples, it is proved the presence of HPV deoxyribonucleid acid (HPV DNA) was found in $99.7 \%$ cases and was dominated by types 16, 18, 31 and 45, this shows the role of high-risk HPV in the development of cervical cancer (Lipinwati, 2014).

Human papillomavirus (HPV) is a double-stranded, non-envelope DNA viruses measuring around 7,200-8,000 base pairs. It enveloped in capsid protein which is composed of L1 protein (major capsules) and L2 protein (minor capsid). The viral genome is divided into 3 regions, namely non-coding regions (initial regulation) or also known as long-control regions (LCR) of 400-1.000 bp, the second region is an initial region consisting of an Early Protein Open Reading Frame (ORF) such as E1, E2, E4, E5, E6 and E7, the third region is the region of late protein that encodes L1 and L2 proteins which form a viral capsids or viral envelopes, in which L1 and L2 capsids play a role in the transmission of HPV viruses (Blitzer et al., 2014).

L1 and L2 proteins have assembly properties into virus-like particles (VLP) that are important in eliciting effective immune responses; this has been used as an ideal target for HPV vaccines. The discovery of nucleotide differences in HPV variants lead to changes in amino acids that can interfere the structure, specific viral functional or antigenic characteristics which are considered important to distinguish potential transmission and to define epitopes that are relevant to vaccine design (Pillai et al., 2009, Buck et al., 2013)

Structural diversity present on the surface of L1 protein between different papillomavirus species is believed to depict the evolution of virus's mutations that are antigenic diversity (Faust and Dillner, 2013 Frazer, 2014; Choi and Park, 2016).

Several studies have proven there are variations in the HPV-16 L1 gene in several countries. These L1 gene variations can affect viral binding that affect the structure or adjustment of proteins and ultimately lead to changes in biological function including host immunological recognition and affect the effectiveness of existing vaccines. According to El aliani's study, out of 35 samples, there are 17 nucleotide changes occurred, namely silent mutation and 5 missense mutations, the five missense mutations are A / C (6694), G / A (6801), G / A (6819), ATG 
Insertion (6903), and GAT Deletions (6950). But none of the 5 missense mutations affected the L1 immunogenic region, while A / C substitution (6694) in loop H-1 showed the potential impact of mutations to the effectiveness of existing anti-HPV vaccines (El-Aliani, 2017)

\section{Method}

This research is a descriptive design study that analyzes deoxyribonucleac acid (DNA) of Human papillomavirus 16 which begins by isolating the network of cervical cancer patients conducted from February 2018 to August 2018 in the Microbiology Laboratory of the Faculty of Medicine, Andalas University, Padang using the Invitrogen kit.

This research has obtained ethical approval from the ethical committee Faculty of Medicine, University of Riau (089/UN.19.5.1.1.8/UEPKK/2018). An informed written consent was taken from each participant. A total of 110 patients were enrolled.

Identified HPV-16 DNA isolates were amplified using three primer pairs, Table 1 self-designed with PCR settings, Initial denaturation at 94 C for 5 minutes, Denaturized at $95^{\rrbracket} \mathrm{C}$ for 30 seconds, Annealing at $56^{\llbracket} \mathrm{C}$ for 45 seconds, Extension at $72^{\natural} \mathrm{C}$ for 1 minute Post Extension at temperature of $72^{\llbracket} \mathrm{C}$ for 10 minutes, repeatedly for 35 cycles. To see the results of the Polymerase Chain Reaction (PCR), an electrophoresis device using $0.8 \%$ agarose gel was used.

Table 1

L1 primary genes of HPV-16

\begin{tabular}{|lll|}
\hline Primer Type & Primer Position & Primer Measurement \\
\hline HPV-16 L1 Gene specific primary I & F : AGTTCCAGGGTCTCCACAAT & $718 \mathrm{bp}$ \\
& R : TCAACCATATCACCATCCTGAA & \\
\hline HPV-16 L1 Gene specific primary II & F : CTAGTG AGG CCACTGTCTACTT & $1000 \mathrm{bp}$ \\
& R : TCCCCATGTCGTAGGTACTCCTTA & \\
\hline HPV-16 L1 Gene specific primary III & F : AACCTTATTGGTTACAACGAG & $751 \mathrm{bp}$ \\
& R : GCATGACACAATAGTTACACAAGC & \\
\hline
\end{tabular}

The PCR results are processed through a sequencing process to obtain nucleotide base sequence sequences from the HPV-16 L1 gene. The process of analyzing the results of sequencing data use Bioedit software (version 7.0.4.1), NCBI BLAST, CLUSTALX, and for the construction of phylogenetic trees we use software and MEGA 6 so that phylogenetic trees can be arranged. Phylogenetic trees were made based on sequences of HPV-16 and their genetic relationship by comparing the sequence of nucleotide bases from the HPV-16 L 1 gene isolates of cervical cancer patients from another countries.

\section{Results}

From the results of the amplification using three pairs of forward and riverse primers, DNA fragments of different sizes were obtained, primer I 718 bp, primary II 1000 bp, primary III 751 bp (Fig. 1a, 1b, 1c). The sequence data of nucleotide base pairs isolates samples obtained from the sequencing results were compared with the reference sequences of the HPV-16 L1 gene in the GenBank (K02718.1). After being analyzed, we obtained a sequence size of $1596 \mathrm{bp}$. Based on sequencing analysis, it was found that all isolates sample experienced SNPs in their DNA sequences, where not all nucleotide bases match with the reference sequence HPV-16 (K02718.1. These SNPs have the potential to affect the amino acid composition (Table 2). These results are processed in the CLUSTALX and MEGA 6 programs. We analyze genetic relationship by making phylogenic trees of HPV-16 L1 gene using variants from Asian-Americans (AA), Europe (E) and Africa (Af). 
Table 2

The variation of HPV-16 L1 gene isolate samples mutation

\begin{tabular}{|lllll|}
\hline Mutation & Position & Total & (\%) & Sample \\
\hline $\begin{array}{l}\text { ACT } \\
\text { Insertion }\end{array}$ & 6901 & $26 / 26$ & 100 & All isolate samples \\
$\begin{array}{l}\text { SNPs } \\
\text { C/G }\end{array}$ & 6240 & $26 / 26$ & 100 & All isolate samples \\
\hline $\begin{array}{l}\text { SNPS } \\
\text { A/G }\end{array}$ & 6432 & $26 / 26$ & 100 & All isolate samples \\
$\begin{array}{l}\text { SNPS } \\
\text { T/G }\end{array}$ & 6688 & $3 / 26$ & 11,5 & HPV06, 17, 193 \\
$\begin{array}{l}\text { SNPS } \\
\text { C/T }\end{array}$ & 6823 & $23 / 26$ & 88 & HPV03,06,09,17,105,164,172,178,179,180,184,185,186,189,190,191,192,193,194,195,196,197,198 \\
$\begin{array}{l}\text { GAT } \\
\text { Deletion }\end{array}$ & 6953 & $26 / 26$ & 100 & All isolate samples \\
\hline
\end{tabular}

\section{Discussion}

In this study, it was found that $74.3 \%$ of the combined isolate samples, from 35 isolates of the HPV DNA samples, 26 isolates of the samples were infected by Human papillomavirus type 16 . While the results of the prevalence of research conducted in India were $95.6 \%$ or from 231 positive samples HPV there are 221 positive samples of HPV-16 (Kumar., Et al. 2015).

HPV type 16 is a type of HPV that often infects cervical tissue which can cause cervical cancer. HPV-16 is the type that most often infects cervical tissue with prevalence almost the same as HPV-18 (70-80\%). This virus can infect cervical tissue with infection of one genotype or several genotypes at once (Pradita et al., 2014)

L1 of HPV-16 and HPV-18 are mostly used in developing prolactive vaccines to suppress HPV infections which have been widely implemented in various countries. This is based on the ability of the L1 gene to produce itself like the virus itself but does not have the viral genome to infect but instead elicits an immune response. Previous studies in Morocco have found that the diversity of HPV-16 is very high and illustrates phylogenic to the regions of Europe (E), Africa (Af), and North America (NA-1). However there are no studies that provide information on L1 variants in Morocco that can affect the effectiveness of existing vaccines. Genomic analysis of the L1 HPV-16 sequence in the sample showed changes from 17 nucleotides including missense mutations A / C (6694), G / A (6801), G / A (6819), ATG insertion (6903), and GAT deletions (6950). In all, 12 sillent mutations were found from various studies in India, the Netherlands and Brazil. The interesting thing is that all the samples analyzed are different from the reference sequence with the insertion of the ATC codon at position 6903 and the deletion of GAT at position 6951 (El-Eliani et al., 2017)

Based on the analysis of the 26 isolates sample sequence compared with reference K02718.1, mutations were found along the $1596 \mathrm{bp}$ sequence tested. This causes molecular variations. Variations that occur in the form of SNPs (Single Nucleotide Polymorphism) in all isolates of the sample in the form of C / G (6240), A / G (6432), T / G (6686), C / T (6823), C / T (6823) substrate sequences occur along the length of the sample isolates observed can cause changes in amino acids and the insertion of nucleotide bases ACT (6901) and followed by GAT base deletions (6953) T deletions (5786) can be seen in Table 2.

Research by Hirose et al., (2018) reported that changes in certain nucleotide sequences which indicate substitution of $\mathrm{C}$ to $\mathrm{T}$, mostly produce missense mutations but do not affect the nature of the virus. Changes that occur where purines replace purines or pyrimidines with pyrimidines are known as transition mutations where occur by tautometric shifts on a DNA basis (Griffith et al., 2000). Persistent infection with high-risk HPV is associated with precancerous growth in cervical cancer that is common in India. This is due to the fact that there are variations in HPV type 16 in HPV genes in certain geographical regions which cause different oncogenic functions and potentials. From various studies, variations of the HPV-16 T / G substitution can inhibit the normal regulation of host cells, degrade and interact with host proteins.

Research in India also reported an insertion in 6901 by ATC seen at the genome level resulting in insertion at 448 in amino acids that produce serine, this change also seen in all GAT removal / deletion samples which occurred at 6590 genome level which caused removal at 465 aspartate amino acids which was seen in $100 \%$ of the sample. These insertions and deletions have not been reported in previous studies. (Pillai et al., 2019) 
Of all the mutations that occurred along the isolate sample sequence, it was found that the most common insertion was the insertion of the ATC base of all the isolate samples, it also found deletions of GAT nucleotide bases in all isolate samples, then the substitution between the purine base and other purines or the purine base with other pyrimidine bases occurred in all $100 \%$ isolate samples. In a study conducted by Gurgel et al. (2015), it is showed the occurrence of ATC insertion and GAT deletions that led to changing of amino acids in 447-threonine / 448-serine and 445-aspartate in all samples. Mutations that occur in these isolates are misense mutations which means changes that occur in nucleotides will change the amino acids produced. Changes to the HPV-16 L1 nucleotide gene can influence capsid structure, introduction of the immune system, and neutralization of the virus (Gurgel et al., 2015).

\section{Conclusions And Suggestions}

There are molecular variations in isolates of HPV type 16 samples from combined samples in the microbiology laboratory of Andalas University, Padang, namely the insertion of ACT (6901) and Deletion (6953) C / G substitution (6240), A / G (6432) C / T (6823) ) found in all isolate samples, and T / G (6686) in the isolate samples of HPV06, HPV17 and HPV179, which can alter the amino acids produced.

\section{Abbreviations}

HPV : Human Papilloma Virus

SNP : Single Nucleotide Polymorphism

A : Adenine

C : Cytosine

G : Guanine

$\mathrm{T}:$ Thymine

DNA : Deoxyribonucleid Acid

LCR : Long-control rRegions

ORF : Open Reading Frame

VLP : Virus-like Particles

PCR : Polymerase Chain Reaction

NCBI : National Center for Biotechnology Information

BLAST : The Basic Local Alignment Search Tool

AA : Asian - American

E : Europe

Af : Africa

NA-1 : North America

\section{Declarations}

\section{ETHICS APPROVAL}

This research has obtained ethical approval from the ethical committee Faculty of Medicine, University of Riau (089/UN.19.5.1.1.8/UEPKK/2018).

\section{CONSENT TO PUBLICATION}

A written informed consent for publication was taken from each participant. 


\section{AVAILABILITY OF DATA AND MATERIAL}

The datasets used and/or analysed during the current study are available from the corresponding author on reasonable request.

\section{COMPETING INTERESTS}

The authors have no conflict of interest to declare.

\section{FUNDING}

This study was funded by Indonesian Ministry Of Research and Technology/University of Riau number 276/UN.19.5.1.3/PP/2018.

\section{AUTHOR CONTRIBUTIONS}

Maya Savira : Study concept and design, acquisition of data, analysis and interpretation of data, statistical analysis, drafting of manuscript and intellectual input

Donel S : Provision of study material or patient, collection and assembly of data, assistance with manuscript completion

Sarah Ovinita : Acquisition of data, administrative support, manuscript writing

Levina Mutia : Acquisition of data, administrative support, manuscript writing

Andani Eka Putra : Data analysis and interpretation, manuscript writing

Yusrawati : Study concept and design, critical review of manuscript, study supervision

Nur Indrawaty Lipoeto : Study concept and design, critical review of manuscript, study supervision

\section{ACKNOWLEDGEMENT}

This study was supported by Departement of Obstetrics and Gynecology Arifin Achmad General Hospital Riau, Microbiology Department Faculty of Medicine University of Riau and Faculty of Medicine Andalas University.

\section{References}

1. Akyar, I., O. Aydin, M. C. Yakicier, Z. T. Kocagoz, U. Ince, dan I. Unsal. Human Papillomavirus Prevalence and Type in Liquid-Based Cervical Samples From Turkish Women in a Selected Risk Group. Turk J Med Sci 43 Hal. 963-970.

2. Blitzer, G. C., M. A. Smith, S. L. Harris, dan R. J. Kimple. 2014. Review of the Clinical and Biologic Aspects of Human PapillomavirusPositive Squamous Cell Carcinomas of the Head and Neck. Int J Radiation Oncol Biol Phys, Vol. 88 (4) Hal. $761-770$.

3. Bruni, L., Barrionuevo-Rosas, L., Serrano, B., Gomez D, Munoz J, Bosch Fx dan de Sanjose S. 2017. Human papillomavirus and Related diseases report in Indonesia. Barcelona : ICO Information Center on HPV and Cancer.

4. Choi, Y. J., S. Park. 2016.Clinical Significance of Human Papillomavirus Genotyping. J Gynecol Oncol. $27(2): e 21$

5. El-Aliani, A., M.A El Alaoui, I. Chaoui, M.M Ennaji, M. Attaleb, M. El Mzibri. 2017. Naturally Occurring Capsid Protein Variants L1 of Human papillomavirus Genotype 16 in Morocco. Bioinformation. 13 : 241-48

6. Faridi, R., A. Zahra, K. Khan dan M. Idrees. 2011. Oncogenic Potential of Human Papillomavirus (HPV) and its Relation with Cervical Cancer. Virologi Jurnal $8: 269$

7. Faust H., dan Dillner. 2013. Mutations in Human papillomavirus type 16 L1 Hypervariable surface-exposed Loops Affect L2 Binding and DNA Encapsidation. Journal of General Virology. 94 : 1841-49.

8. Ferlay, J., I. Soerjomataram, R. Dikshit, S. Eser, C. Mathers, M. Rebelo, D. M. Parkin, D. Forman dan F. Bray. 2015. Cancer Incidence and Mortality Worldwide: Ources, Methods and Major Patterns in GLOBOCAN 2012. Int. J. Cancer: 136, E359-E386

9. Frazer, I. H. 2014. Development and Implementation of Papillomavirus Prophylactic Vaccines. J Immunol 192 Hal. $4007-4011$. 
10. Griffiths AJF, miller JH,Suzuki DT. An Indtroduction to genetic Analysis.7thedition.Newyork: W. H. Freeman;2000.Spontaneous mutations. Availablefrom: http://www.ncbi.nml.nih.gov/books/NBK21897

11. Gurgel, A.P.A.D., B.S. Chagas, C.M. do Amaral, K.C.G. Nascimento, R.L.S. Leal, J.C.S. Neto, M.T.C. Muniz, dan A.C. de Freitas. 2015. Prevalence of Human Papillomavirus Variants and Genetic Diversity in the L1 Gene and Long Control Region of HPV16, HPV31, and HPV58 in North-East Brazil. Biomed research International volume 2015.

12. Kumar, N. 2016. Cervical Cancer; a Nightmare for Womanhood: Review of RecentAdvances. Women's Health \& GynecologyVolume 2 (2) 19.

13. 2014 Diangnosis Molekuler Human Papillomavirus (HPV) Penyebab Kanker Serviks. JMJ. 2 : 78 - 86.

14. Manga, M. M., A.Fowotade, Y. M. Abdullahi, A. U. El-nafaty, D. B. Adamu, H. U. Pindiga, R. A. Bakare dan A.O. Osoba. 2015. Epidemiological Patterns of Cervical Human Papillomavirus Infection Among Women Presenting for Cervical Cancer Screening in North-Eastern Nigeria. Infectious Agents and Cancer 10(39) 1-9

15. Nurcahyanti, A. D.R. 2016. Cervical Cancer: The Case in Indonesia and Natural Product- Based Therapy. Journal of Cancer Biology \& Research 4(1): 1078.

16. Pillai, MR., R. Hariharan, J. M. Babu, S. Lakshmi, M. Patkar, H. Tongaonkar. 2009. Molecular variants of HPV-16 associated with cervical cancer in Indian population. Int. J. Cancer: 125, 91-103

17. Pradita, A., E,Sahiratmadja, S.Suhandono dan H. Susanto. 2014. Sekuen Gen Protein Kapsid Mayor L1 Human Papillomavirus 16 dari Isoalat Klinik Asal Bandung. MKB.46:143-49.

18. Setiawati, D. 2014. Human Papillomavirus dan Kanker Serviks.Al-Sihah : Public Health Science Journal Volum 4(2) Hal. $450-459$.

\section{Figures}

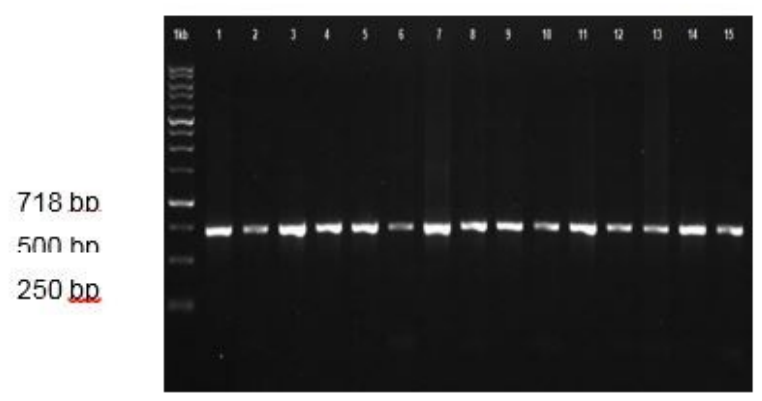

\section{Figure 1}

Primary amplification I

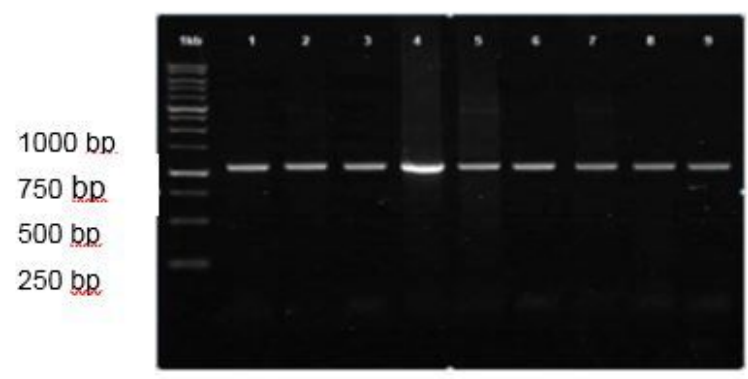

Figure 2

Primary amplification II 


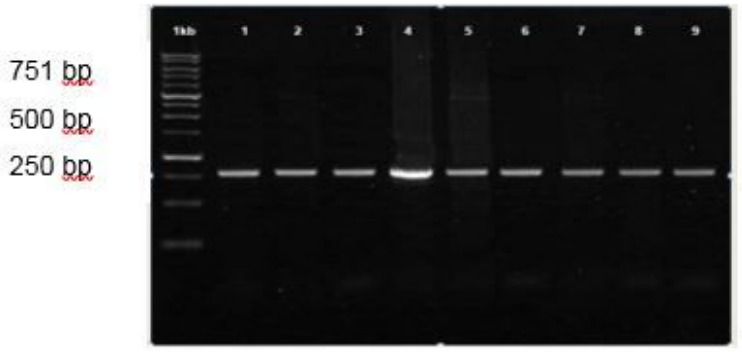

Figure 3

Primary amplification III 